\title{
Atypical evening cortisol profile induces visual recognition memory deficit in healthy human subjects Heather Gilpin 1,2, Daniel Whitcomb ${ }^{2,3}$ and Kwangwook Cho*1,2,3
}

\author{
Address: ${ }^{1}$ Biomedical Science, University of Sheffield, Sheffield, S10 2TN, UK, ${ }^{2}$ Henry Wellcome Laboratories for Integrative Neuroscience and \\ Endocrinology, UK and ${ }^{3}$ The MRC Centre for Synaptic Plasticity, University of Bristol, Bristol, BS1 3NY, UK \\ Email: Heather Gilpin - H.Gilpin@sheffield.ac.uk; Daniel Whitcomb - d.whitcomb.06@bristol.ac.uk; \\ Kwangwook Cho* - Kei.Cho@bristol.ac.uk \\ * Corresponding author
}

Published: 21 August 2008

Molecular Brain 2008, I:4 doi:10.1 186/1756-6606-1-4

This article is available from: http://www.molecularbrain.com/content/l/l/4

(C) 2008 Gilpin et al; licensee BioMed Central Ltd.

This is an Open Access article distributed under the terms of the Creative Commons Attribution License (http://creativecommons.org/licenses/by/2.0), which permits unrestricted use, distribution, and reproduction in any medium, provided the original work is properly cited.
Received: 28 March 2008

Accepted: 21 August 2008

\begin{abstract}
Background: Diurnal rhythm-mediated endogenous cortisol levels in humans are characterised by a peak in secretion after awakening that declines throughout the day to an evening trough. However, a significant proportion of the population exhibits an atypical cycle of diurnal cortisol due to shift work, jet-lag, aging, and mental illness.

Results: The present study has demonstrated a correlation between elevation of cortisol in the evening and deterioration of visual object recognition memory. However, high evening cortisol levels have no effect on spatial memory.

Conclusion: This study suggests that atypical evening salivary cortisol levels have an important role in the early deterioration of recognition memory. The loss of recognition memory, which is vital for everyday life, is a major symptom of the amnesic syndrome and early stages of Alzheimer's disease. Therefore, this study will promote a potential physiologic marker of early deterioration of recognition memory and a possible diagnostic strategy for Alzheimer's disease.
\end{abstract}

\section{Background}

Cortisol levels are maximal in the early morning and minimal in the late evening in humans [1-3]. Dysregulation in the diurnal cortisol rhythm has been associated with depression and pathological aging [4,5]. For example, age-dependent increases in evening cortisol levels have been reported in healthy subjects [6-8]. The study [6] also found a phase advance in the morning acrophase in the aged subject group. In addition, nocturnal increases in cortisol in aged subjects were correlated with significant reductions in hippocampal and temporal lobe volume [9]. Recently, a significant increase of serum cortisol levels during the evening- and night-time was found in demented patients, particularly those with Alzheimer's disease [5].

Previous studies have demonstrated that circadian-mediated cortisol levels also have an important role in cognition in an age-independent manner [10-12]. For example, frequent time-zone travellers who experience disruption to their circadian rhythm had significantly higher cortisol levels during their average working day, which was associated with cognitive deficits and right temporal lobe atrophy $[10,11]$. However, little is known whether an atypical rhythm of diurnal cortisol levels is associated with cognitive deficits and neurological insults. The present study 
analyzed the relationship between diurnal cortisol levels and cognition in healthy female subjects.

\section{Results}

Subjects were 22- to 66-year-old women (Mean age $=40$ yrs, age deviation $=12$ yrs, $\mathrm{n}=44$ subjects) who had no neurological or psychiatric illness. Firstly, the present study analysed salivary-cortisol levels at three different time-points during the day ( $8 \mathrm{am}, 2 \mathrm{pm}$ and $10 \mathrm{pm})$, collected from two independent weeks (for more details see method). Since cortisol levels peak within an hour after wakeup, and decrease toward to bottom level at late evening [10], three different time saliva collecting points ( $8 \mathrm{am}, 2 \mathrm{pm}$ and $10 \mathrm{pm}$ ) will represent a major diurnal cortisol rhythm during the day. To avoid sleep/wake cycle dependent variance of diurnal cortisol rhythm, subjects were set their wakeup time at 7:30 am and sleep time at 11:00 pm. In thirty-three subjects, cortisol level at $10 \mathrm{pm}$ is the lowest profile within three time points $(2.9 \pm 0.2$ $\mathrm{nmol} / \mathrm{L}$, filled symbol, Figure $1 \mathrm{~A})$. In eleven subjects, however, cortisol level at $10 \mathrm{pm}$ is equal to higher than that of $2 \mathrm{pm}(6.4 \pm 1.5 \mathrm{nmol} / \mathrm{L}$, opened symbol, Figure 1A). To clarify the pattern of cortisol levels at $10 \mathrm{pm}$, data were renormalized by cortisol levels at $2 \mathrm{pm}$ (low cortisol $_{10 \mathrm{pm}} ; 54 \pm 3 \%$ of $2 \mathrm{pm}$ cortisol level, $\mathrm{n}=33$, filled symbol; high cortisol $10 \mathrm{pm} ; 165 \pm 27 \%$ of $2 \mathrm{pm}$ cortisol level, $\mathrm{n}=11$, opened symbol, Figure 1B). Thus, we divided subjects into two groups based on normalized 10 pm cortisol level (i.e., low cortisol $10 \mathrm{pm}$ group and high cortisol $_{10}$ $\mathrm{pm}$ group). There is no difference in the mean age of the high cortisol ${ }_{10 \mathrm{pm}}$ group and the low cortisol $_{10 \mathrm{pm}}$ group (low cortisol $_{10 \mathrm{pm}}: 40 \pm 2$ years; high cortisol $10 \mathrm{pm}: 40 \pm 4$ years; $\mathrm{P}>0.05$ ).

Next we analyzed whether there was any interaction between cortisol $_{10 \mathrm{pm}}$ and cognition. In the first series of experiments, we tested attention and language in both the low cortisol $10 \mathrm{pm}$ group and the high cortisol $_{10 \mathrm{pm}}$ group. There was no significant difference in correct key response for both the attention, (low cortisol ${ }_{10} \mathrm{pm}$ : $95 \pm 2 \%$ correct response, $\mathrm{n}=32$; high cortisol $_{10 \mathrm{pm}}: 89 \pm 4 \%$ correct response, $\mathrm{n}=11 ; \mathrm{P}>0.05$, Figure $2 \mathrm{~A}$ ) and the language task (low cortisol $10 \mathrm{pm}: 95 \pm 1 \%, \mathrm{n}=31$; high cortisol $_{10 \mathrm{pm}}$ : $92 \pm 1 \%, \mathrm{n}=9 ; \mathrm{P}>0.05$, Figure 2A). Similarly, there was no significant difference in correct key response reaction time between these two groups for both the attention (low cortisol $_{10 \mathrm{pm}}: 442 \pm 22 \mathrm{msec}, \mathrm{n}=32$; high cortisol $_{10}$ $\mathrm{pm}: 463 \pm 27 \mathrm{msec}, \mathrm{n}=11 ; \mathrm{P}>0.05$, Figure $2 \mathrm{~B}$ ) and the lan-

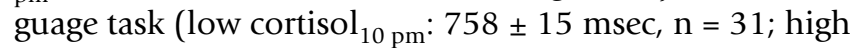
cortisol $_{10 \mathrm{pm}}$ : $746 \pm 29 \mathrm{msec}^{\mathrm{n}}=9 ; \mathrm{P}>0.05$, Figure 2B).

In the next series of experiments, we analyzed visual object recognition memory and spatial memory in both subject groups (Figure 2C). In the novel object discrimination task, there was a significant difference in correct key
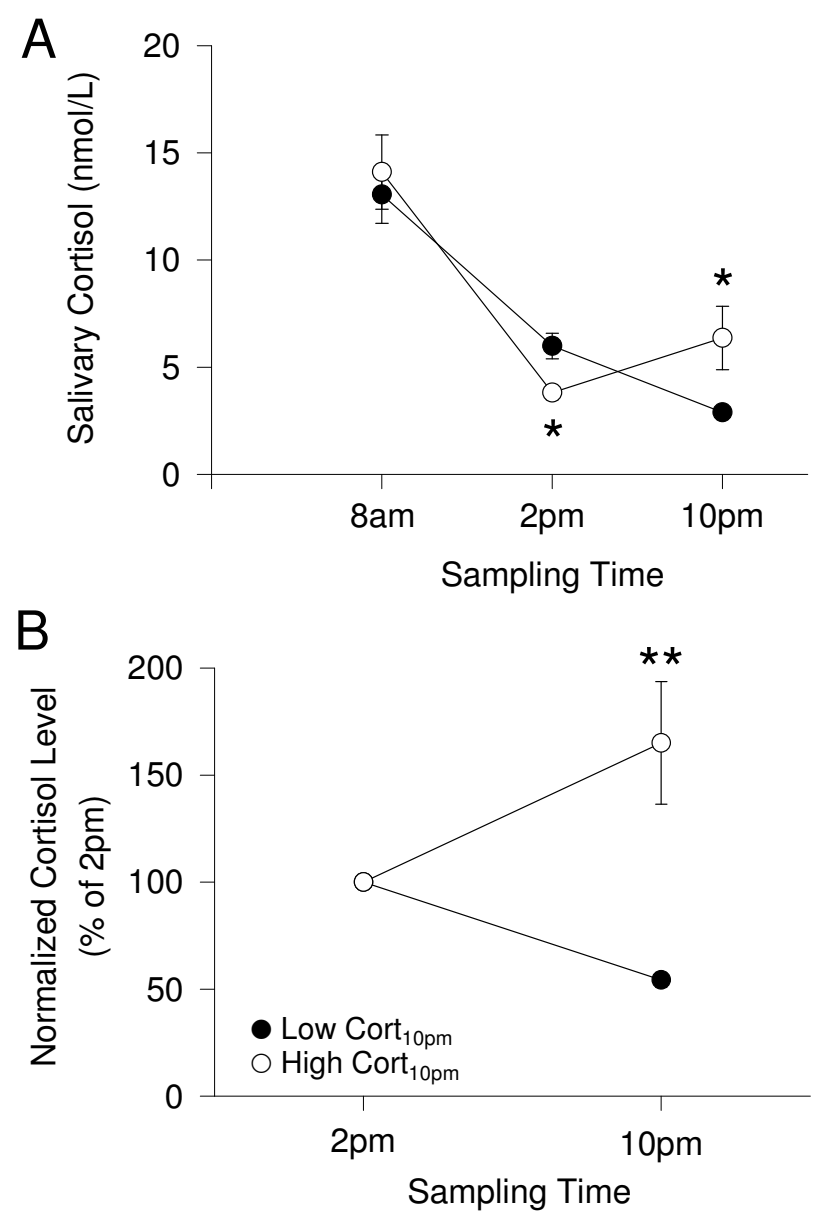

\section{Figure I}

Salivary cortisol level was analysed by means of a cortisol salivary immunoassay kit (for more details, see method). (A) Salivary cortisol samples were collected at three particular time points ( $8 \mathrm{am}, 2 \mathrm{pm}$ and $10 \mathrm{pm})$. Most subjects showed lower cortisol levels at $10 \mathrm{pm}$ compared to that of $2 \mathrm{pm}$ (low cortisol $10 \mathrm{pm}, \mathrm{n}=33$ subjects). Eleven subjects showed higher cortisol levels at $10 \mathrm{pm}$ compared to that of $2 \mathrm{pm}$ (high cortisol $10 \mathrm{pm}$ ). (B) Cortisol 10 pm indicates normalized $10 \mathrm{pm}$ cortisol level (percent of $2 \mathrm{pm}$ cortisol level). Error bars indicate s.e.m. Significant difference at $* \mathrm{P}<$ 0.01 , **P $<0.0001$.

response (low cortisol ${ }_{10 \mathrm{pm}}: 83 \pm 3 \%$ correct response, $\mathrm{n}=$ 33; high cortisol ${ }_{10 \mathrm{pm}}$ : $59 \pm 7 \%$ correct response, $\mathrm{n}=11$; P $<0.005$, Figure. 2C). In contrast, there was no significant difference in spatial memory performance between low cortisol $_{10 \mathrm{pm}}$ and high cortisol $10 \mathrm{pm}$ group (Figure 2C).

Next the relationship between normalized cortisol $_{10 \mathrm{pm}}$ level and percentage correct key response during the novel object discrimination task was examined by regression analysis. A significant correlation was found between these two variables $\left(\mathrm{r}=-0.44, \mathrm{r}^{2}=0.19, \mathrm{P}<0.01, \mathrm{n}=44\right.$, 

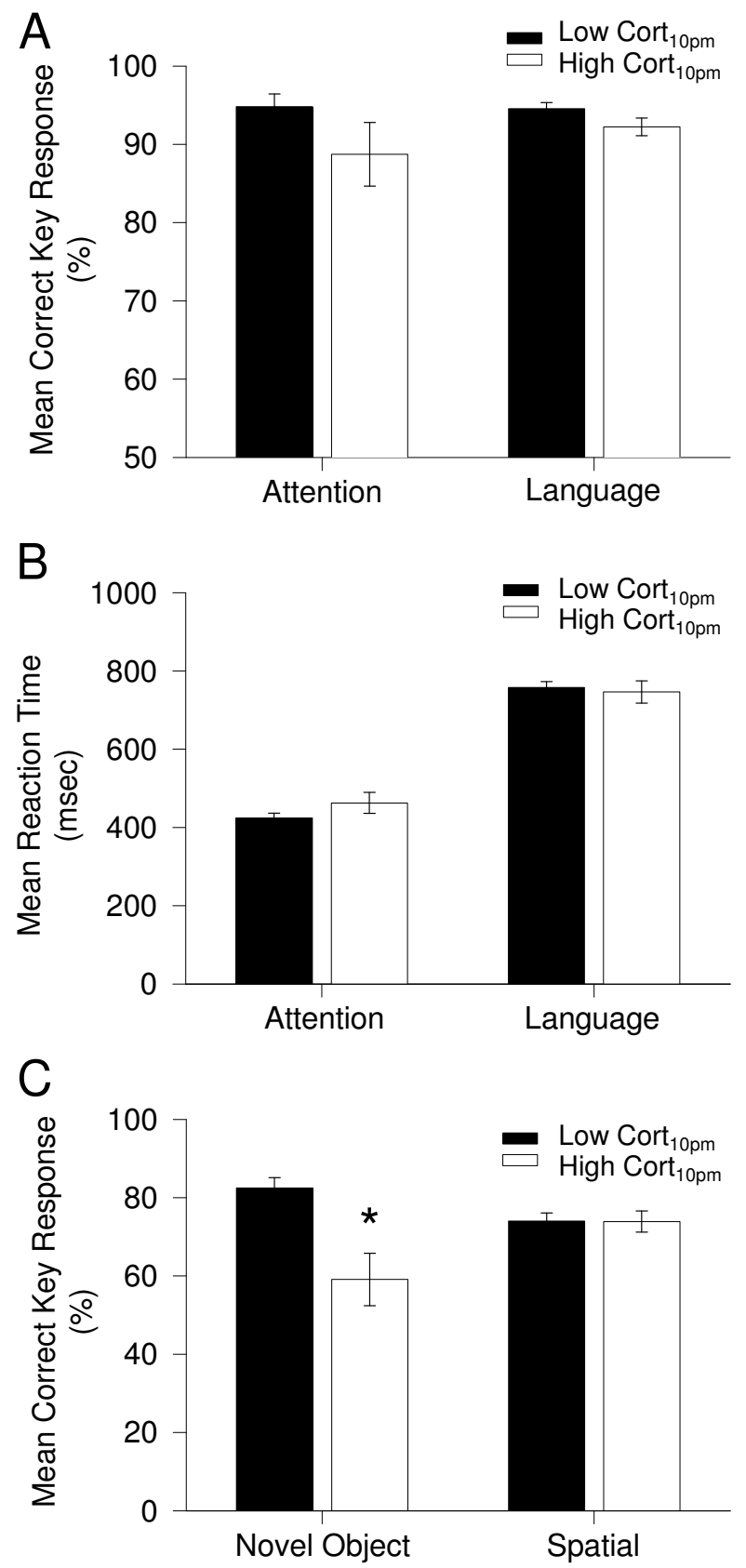

Figure 2

Both the low cortisol ${ }_{10}$ pm subject group and the high cortisol $_{10}$ pm subject group were compared to assess the correct key response and reaction time in cognitive performance. $(A, B)$ Mean ( \pm s.e.m.) correct response and reaction time in two groups. There is no significant difference between the low cortisol 10 pm group and the high cortisol $_{10 \mathrm{pm}}$ group in performance in either the attention or the language task. (C) Low cortisol ${ }_{10}$ pm subjects show a significantly more accurate correct key response than that of high cortisol ${ }_{10}$ pm subjects in the novel object discrimination task. *Significant group difference at $p<0.005$.
Figure 3A). This initial result implies that although high evening cortisol does not influence the recognition of previously-encoded, highly recognisable objects (low cortisol $_{10 \mathrm{pm}}: 97 \pm 1 \%$ correct response, $\mathrm{n}=33$; high cortisol $_{10 \mathrm{pm}}$ : $93 \pm 3 \%$ correct response, $\mathrm{n}=11 ; \mathrm{P}>0.05$ ), it may specifically affect the processing and the ultimate familiarisation of new objects. To examine this further, we analysed the familiarity acquisition time of novel objects in both subject groups (Figure 3B). Firstly, there was no significant group difference in reaction time to the first appearance of a novel object (low cortisol $10 \mathrm{pm}: 873 \pm 19$ $\mathrm{ms}, \mathrm{n}=29$; high cortisol ${ }_{10 \mathrm{pm}}: 888 \pm 65 \mathrm{~ms}, \mathrm{n}=9, \mathrm{P}>0.05$, Figure 3B). However, a significant difference was found in the reaction time to the fourth appearance of the same novel object (low cortisol $10 \mathrm{pm}: 619 \pm 16 \mathrm{~ms}, \mathrm{n}=29$; high cortisol $_{10 \mathrm{pm}}: 703 \pm 31 \mathrm{~ms}, \mathrm{p}<0.05$, Figure $3 \mathrm{~B}$ ). This difference in reaction time was not observed at either the first

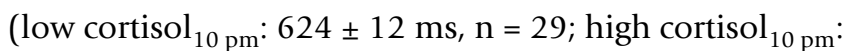
$657 \pm 36 \mathrm{~ms}, \mathrm{n}=10, \mathrm{P}>0.05$, Figure 3C) or the fourth presentation of a familiar object (low cortisol $_{10 \mathrm{pm}}: 547 \pm$ $14 \mathrm{~ms}, \mathrm{n}=29$; high cortisol $_{10 \mathrm{pm}}: 546 \pm 15 \mathrm{~ms}, \mathrm{n}=10, \mathrm{P}>$ 0.05, Figure. 3C).

\section{Discussion}

The present study demonstrates a significant correlation between normalized cortisol $10 \mathrm{pm}$ level and novel object discrimination and recognition. However, there was no significant relationship between cortisol $_{10 \mathrm{pm}}$ level and either attention or language. These results suggest no difference in either generic learning or visual perception between the two subject groups. Since the results are consistent with previous study [11], salivary cortisol level associated with the circadian rhythm may have a specific role in non-semantic cognition. As yet, we do not know whether evening cortisol level has a particularly important role in non-semantic cognition. A recent study suggests that acute stress regulates memory in a circadian rhythmmediated manner [12]. Similarly, the current investigation also indicates that the timing of stress may be important in determining its effects on certain aspects of memory. Thus, the differentiation of circadian-mediated cortisol levels may have a critical role in the regulation of non-semantic cognition. It is still a matter of further investigation whether high cortisol $_{10}$ pm levels are due to individual differences in diurnal rhythm or basal stress levels [13], or an indication of natural aging in normal women $[6,14,15]$.

The diurnal pattern of cortisol is considered relatively robust but is shown to be disrupted in shift workers [16$18]$, transmeridian flyers $[11,19]$ and disease states such as Alzheimer's disease $[5,20]$ and depression [21,22]. In our study, we did notice that high cortisol $_{10} \mathrm{pm}$ group had lower cortisol at $2 \mathrm{pm}$ but higher at $10 \mathrm{pm}$. This suggests that high cortisol $_{10 \mathrm{pm}}$ group has a different diurnal fre- 

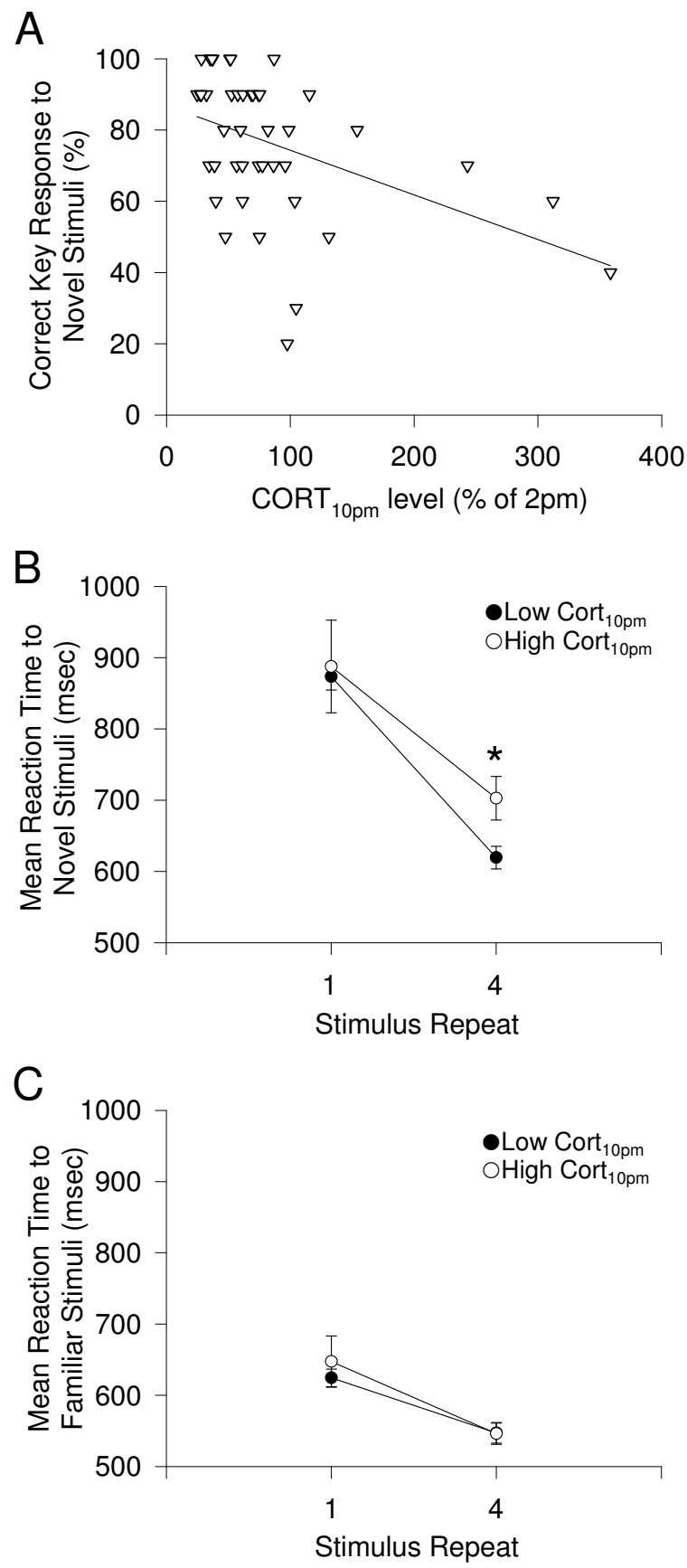

Figure 3

Correlation with evening corticosterone level and familiarity discrimination. (A) Cortisol ${ }_{10 \mathrm{pm}}$ level was negatively correlated with performance in the novel object discrimination across the whole cohort $\left(r=-0.44, r^{2}=0.19, P<\right.$ $0.01, n=44)$. (B) Mean ( \pm s.e.m.) reaction time to novel stimuli. The high cortisol $10 \mathrm{pm}$ group were significantly slower at responding to the fourth repeated presentation of a novel object. *Significant group difference at $p<0.05$. (C) Mean ( \pm s.e.m.) reaction time to familiar object stimuli. There was no significant group difference $(P>0.05)$. Filled bars indicate low cortisol $_{10 \text { pm }}$ group, and open bars indicate high cortisol $10 \mathrm{pm}$ group. quency of cortisol than that of low cortisol $_{10 \text { pm }}$ group. Alternatively cortisol cycle has shifted. Interestingly, variations in the diurnal pattern of salivary cortisol have been repeatedly identified among healthy populations. In these studies, most adults have a 'normal' cortisol cycle but a subset display an 'atypical' cortisol cycle [23-25]. Therefore, some people do not have the expected diurnal rhythm of cortisol secretion which is what was detected in the current investigation [25].

In one particular study [26], the majority of a subject group consisting of older individuals with memory complaints presented an atypical cortisol profile that was characterised by a normal morning peak, with evening levels that did not reach the typical low nadir phase. This implies that atypical diurnal cortisol release may have significant effects on memory function.

Why is high evening cortisol in particular associated with recognition memory deficits? Recent studies have showed that stress induced in the morning, but not the afternoon, is associated with memory deficits $[12,27,28]$. In these studies, the observed impacts are due to acute manipulations of cortisol that are reversible. However, little is known about whether or not chronic stress is more detrimental at a certain time point during the day. Potentially, high cortisol levels at a time when they should be low may have negative impact on cognitive function. Alternatively, high evening cortisol may well interfere with sleep duration or quality, lack of which is associated with cognitive deficits [29]. In support of this, it was found that a lightening of sleep is accompanied by increases in cortisol, and the ability to enter REM (rapid eye movements) sleep cycles requires low cortisol levels at night, which are characteristic of this time of day [30].

The next question to answer is how does high cortisol $_{10 \mathrm{pm}}$ selectively affect object recognition with no effect on other aspects of cognition? High cortisol ${ }_{10}$ pm may selectively induce transient changes in synaptic plasticity in specific neuronal circuitry such as perirhinal cortical synapses, which have been hypothesised as being an important brain region for visual object recognition [31]. These cortisol levels may be not high enough or long enough in duration to regulate synaptic plasticity in other neuronal circuitries, such as the hippocampus. There is evidence to support this hypothesis; in rodents and non-human primates, the perirhinal cortical region showed the highest density of glucocorticoid receptor (GR)-immunoreactive and GR-mRNA-containing cells than other brain regions $[32,33]$. Therefore, the pharmacological feature of GR activation in the perirhinal cortex may be a potential answer. 


\section{Conclusion}

Taken together, salivary cortisol level at the evening phase of the diurnal rhythm may have an important role in early deterioration of visual recognition memory in healthy female subjects. The loss of recognition memory, which is vital for everyday life, is a major symptom of the amnesic syndrome and early stages of Alzheimer's disease [31]. Therefore, this study will promote a potential physiologic marker of early deterioration of recognition memory. It will be of future interest to reveal whether this deterioration of recognition memory is due to neurological insults in specific brain regions.

\section{Methods \\ Subjects}

The subjects volunteered to participate in this study and had no medication history. Each subject filled in a questionnaire that provided information on health and lifestyle. This study was conducted in accordance with the Declaration of Helsinki.

\section{Cortisol Measurement}

The subjects were asked to collect saliva samples at three particular time points ( $8 \mathrm{am}, 2 \mathrm{pm}$ and $10 \mathrm{pm})$ on two normal working days from two independent weeks. To avoid season-mediated light/dark cycle variance, saliva samples were collected between May - August of the year. Saliva was collected by means of a sterile microbiological swab (Bibby Sterilin Ltd, Stafford, UK). Subjects were asked to keep samples in a fridge until collection. Saliva was extracted from the swab by centrifugation at 2000 $\mathrm{rpm}$ at a temperature of $4^{\circ} \mathrm{C}$ for 6 minutes. Salivary cortisol was determined by means of a cortisol salivary immunoassay kit (Salimetrics Ltd, Pennsylvania, USA) and read in a luminometer. Each sample was determined in duplicate to identify potential sample loading errors.

\section{Cognitive Tasks}

Before starting the experiment, the subjects were fully informed as to how to respond to the tasks by means of a visual instruction sheet. Subjects also completed a practice version of each task to ensure familiarisation with the procedure. The tasks were conducted with an Apple Macintosh computer using Macintosh stimulus presentation software (SuperLab; Cedrus, Wheaton, MD) [34] which presents images for the different cognitive tasks (for more details see Cho et al., 2000; Cho, 2001). All participants were tested in the afternoon between the hours of $2 \mathrm{pm}$ and $5 \mathrm{pm}$ to minimize possible differences in performance due to diurnal changes in cortisol.

Each visual task began with a 5 sec presentation of a black cross in the centre of the screen to hold the subject's attention. Test pictures were presented in a pseudorandom and counter-balanced order. The tasks required the subjects to choose the correct key responses. In the attention task,

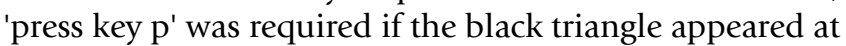
the top of the square, and 'press key q' if it appeared on the bottom. No response was required for any other image (i.e., neutral stimulation). The language task was based on one previously used [35] and involved an appropriate key response to presentation of a written word. Half of the words referred to man-made items (e.g., "scissors") while half were natural items (e.g., "cat"). Subjects were required to 'press key $\mathrm{p}$ ' in response to a word referring to a natural item, and 'press key q' in response to a manmade item. No response was required for a neutral stimulation (black cross). All of the stimuli were highly familiar, concrete nouns according to the MRC psycholinguistic database [36].

Visual recognition memory was analysed using photographed images of novel and familiar objects. Images for the object recognition memory tasks were obtained from the websites http://www.images.google.com and http:// www.gettyimages.com. Familiar images were of everyday items (e.g., a chair or a shoe) while novel objects were obscure images the subjects were unlikely to have encountered ever before. The object discrimination task was based on the 'object familiarity detection task' used by Laatu and colleagues [37]. In this task the subject was presented with a sequence of familiar and novel objects that were shown in a pseudorandom and counterbalanced order. The subject was asked to decide whether the picture presented was a familiar object or not by pressing one of two keys on the computer keyboard. Therefore correct performance required decisions based on whether or not the presented shape has a representation in the subject's longterm memory [37]. For data analysis, responses to familiar images and responses to novel images were determined separately. The familiarity acquisition task used the same format as the object discrimination task but in this case, some images were repeated at later points in the sequence. Appearances of the same image were always parted by at least 7 other images (which didn't differ significantly between novel and familiar images). The reaction time to repeated presentations of novel images gave an indication whether or not the item was becoming familiar. A second difference between this task and the object discrimination task was that the subjects were asked to silently name the objects presented to them. If they could name them (familiar object) they were required to press one key, and if they were unable to name them (novel object) they were to press the other key. As this task concerned the reaction time to repeated novel images, this naming method was adopted in order to encourage the subjects to press the novel key if the image was indeed novel [37]. Essentially the subjects were still categorising the objects as either familiar or novel. By the fourth presentation of the novel image the subject begins to recognise the object and thus 
respond more quickly to the image. In this recognition task the subjects are unaware that they are encoding visual information about the objects. In addition, they are not aware that they are being tested for their memory of novel images. Therefore this task is an incidental encoding delay task.

In the spatial task, subjects were required to 'press key p' if the second presentation of a set of images were in the same position as when they first appeared, and 'press key $q^{\prime}$ if an image had changed its position. Repetitions of the same set of images were separated by a presentation of a black cross for a duration of 8 secs. The accuracy of correct responses (percentage) and reaction time (msec) were measured by the computer.

\section{Statistical analysis}

Statistical analyses were carried out using Student's nonpaired $t$ test, the Mann-Whitney U-test and regression analysis. Data are presented as Mean \pm s.e.m. $P<0.05$ was taken as the level of significance throughout the analysis.

\section{Authors' contributions}

HG carried out all of the experiments. DW confirmed statistics and coordinated the manuscript. KC conceived the study, supervised all experiments and coordinated the manuscript. All authors assisted with writing the manuscript.

\section{Acknowledgements}

This work was supported by the Royal Society (KC), and UK Alzheimer's Research Trust (KC). DW is a recipient of UK Alzheimer's Research Trust $\mathrm{PhD}$ scholarship.

\section{References}

I. Edwards S, Clow A, Evans P, Hucklebridge F: Exploration of the awakening cortisol response in relation to diurnal cortisol secretory activity. Life Sci 200I, 68:2093-2I03.

2. Edwards S, Evans P, Hucklebridge F, Clow A: Association between time of awakening and diurnal cortisol secretory activity. Psychoneuroendocrinol 200I, 26:613-622.

3. Clow A, Thorn L, Evans P, Hucklebridge F: The awakening cortisol response: methodological issues and significance. Stress 2004 , 7:29-37.

4. Gomez RG, Fleming SH, Keller J, Flores B, Kenna H, DeBattista C, Solvason B, Schatzberg AF: The neuropsychological profile of psychotic major depression and its relation to cortisol. Biol Psychiatry 2006, 60:472-478.

5. Magri F, Cravello L, Barili L, Sarra S, Cinchetti W, Salmoiraghi F, Micale G, Ferrari E: Stress and dementia: the role of the hypothalamicpituitary-adrenal axis. Aging Clin Exp Res 2006, I8:167-170.

6. Van Cauter E, Leproult R, Kupfer DJ: Effects of gender and age on the levels and circadian rhythmicity of plasma cortisol. J Clinc Endocrinol Metabol 1996, 8 I:2468-2473.

7. Deuschle M, Gotthardt U, Schweiger U, Weber B, Korner A, Schmider J, Standhardt $\mathrm{H}$, Lammers $\mathrm{CH}$, Heuser I: With aging in humans the activity of the hypothalamus-pituitary-adrenal system increases and its diurnal amplitude flattens. Life Sci 1997, 61:2239-2246.

8. Giordano R, Bo M, Pellegrino M, Vezzari M, Baldi M, Picu A, Balbo M, Bonelli L, Migliaretti G, Ghigo E, Arvat E: Hypothalamus-pituitaryadrenal hyperactivity in human aging is partially refractory to stimulation by mineralocorticoid receptor blockade. J Clinl Endocrinol Metab 2005, 90:5656-5662.

9. Magri F, Terenzi F, Ricciardi T, Fioravanti M, Solerte SB, Stabile M, Balza G, Gandini C, Villa M, Ferrari E: Association between changes in adrenal secretion and cerebral morphometric correlates in normal aging and senile dementia. Dement Geriatr Cogn Disord 2000, I I:90-99.

10. Cho K: Chronic 'jet lag' produces temporal lobe atrophy and spatial cognitive deficits. Nat Neurosci 200I, 4:567-568.

II. Cho K, Ennaceur A, Cole JC, Suh CK: Chronic jet lag produces cognitive deficits. J Neurosci 2000, 20(6):RC66.

12. Maheu FS, Collicutt P, Kornik R, Moszkowski R, Lupien SJ: The perfect time to be stressed: a differential modulation of human memory by stress applied in the morning or in the afternoon. Prog Neuropsychopharmacol Biol Psychiatry 2005, 29: | 28I- | 288.

13. Putman P, Van Honk J, Kessels RP, Mulder M, Koppeschaar HP: Salivary cortisol and short and long-term memory for emotional faces in healthy young women. Psychoneuroendocrinol 2004, 29:953-960.

14. Sherman B, Wysham C, Pfohl B: Age-related changes in the circadian rhythm of plasma cortisol in man. J Clin Endocrinol Metab 1985, 61:439-443.

15. Lupien SJ, de Leon M, de Santi S, Convit A, Tarshish C, Nair NP, Thakur M, McEwen BS, Hauger RL, Meaney MJ: Cortisol levels during human aging predict hippocampal atrophy and memory deficits. Nat Neurosci 1998, I:69-73.

16. Goh VH, Tong TY, Lim CL, Low EC, Lee LK: Circadian disturbances after night-shift work onboard a naval ship. Military Medicine 2000, 165:101-105.

17. Harma MI, Hakola T, Akerstedt T, Laitinen JT: Age and adjustment to night work. Occup Environ Med 1994, 5 I:568-573.

18. Hennig J, Kieferdorf P, Moritz C, Huwe S, Netter P: Changes in cortisol secretion during shiftwork: implications for tolerance to shiftwork? Ergonomics 1998, 41:610-621.

19. Harma M, Laitinen J, Partinen M, Suvanto S: The effect of four-day round trip flights over 10 time zones on the circadian variation of salivary melatonin and cortisol in airline flight attendants. Ergonomics 1994, 37: 1479-1489.

20. Ferrari E, Arcaini A, Gornati R, Pelanconi L, Cravello L, Fioravanti M, Solerte SB, Magri F: Pineal and pituitary-adrenocortical function in physiological aging and in senile dementia. Exp Gerontol 2000, 35: I239-1250.

2I. Siever LJ, Davis KL: Overview: toward a dysregulation hypothesis of depression. Am J Psychiatry 1985, I42:1017-1031.

22. Koenigsberg HW, Teicher MH, Mitropoulou V, Navalta C, New AS, Trestman R, Siever LJ: 24-h Monitoring of plasma norepinephrine, MHPG, cortisol, growth hormone and prolactin in depression. J Psychiatric Res 2004, 38:503-5II.

23. Ice GH, Katz-Stein A, Himes J, Kane RL: Diurnal cycles of salivary cortisol in older adults. Psychoneuroendocrinol 2004, 29:355-370.

24. Smyth JM, Ockenfels MC, Gorin AA, Catley D, Porter LS, Kirschbaum C, Hellhammer DH, Stone AA: Individual differences in the diurnal cycle of cortisol. Psychoneuroendocrinol 1997, 22:89-105.

25. Stone AA, Schwartz JE, Smyth J, Kirschbaum C, Cohen S, Hellhammer $D$, Grossman S: Individual differences in the diurnal cycle of salivary free cortisol: a replication of flattened cycles for some individuals. Psychoneuroendocrinol 200I, 26:295-306.

26. Fiocco AJ, Wan N, Weekes N, Pim H, Lupien SJ: Diurnal cycle of salivary cortisol in older adult men and women with subjective complaints of memory deficits and/or depressive symptoms: relation to cognitive functioning. Stress 2006, 9: $143-152$.

27. Lupien SJ, Gillin C], Hauger RL: Working memory is more sensitive than declarative memory to the acute effects of corticosteroids: a dose-response study in humans. Behav Neurosci 1999, II 3:420-430.

28. Lupien SJ, Wilkinson CW, Briere S, Menard C, Ng Ying Kin NM, Nair NP: The modulatory effects of corticosteroids on cognition: studies in young human populations. Psychoneuroendocrinol 2002, 27:40I-4I6.

29. Ohayon MM, Vecchierini MF: Normative sleep data, cognitive function and daily living activities in older adults in the community. Sleep 2005, 28:98I-989.

30. Gronfier C, Simon C, Piquard F, Ehrhart J, Brandenberger G: Neuroendocrine processes underlying ultradian sleep regulation in man. J Clin Endocrinol Metab 1999, 84:2686-2690. 
31. Brown MW, Aggleton JP: Recognition memory: what are the roles of the perirhinal cortex and hippocampus? Nat Rev Neurosci 200I, 2:5I-6I.

32. Morimoto M, Morita N, Ozawa H, Yokoyama K, Kawata M: Distribution of glucocorticoid receptor immunoreactivity and mRNA in the rat brain: an immunohistochemical and in situ hybridization study. Neurosci Res 1996, 26:235-269.

33. Sanchez MM, Young LJ, Plotsky PM, Insel TR: Distribution of corticosteroid receptors in the rhesus brain: relative absence of glucocorticoid receptors in the hippocampal formation. J Neurosci 2000, 20:4657-4668.

34. Haxby JV, Parasuraman P, Lalonde F, Abboud H: Superlab: general purpose software for human experimental psychology and psychological testing. Behav Res Methods Instrum Comput 1993, 25:400-405.

35. Devlin JT, Rushworth MF, Matthews PM: Category-related activation for written words in the posterior fusiform is task specific. Neuropsychologia 2005, 43:69-74.

36. Coltheart V, Evans JS: An investigation of semantic memory in individuals. Mem Cognit 1981, 9:524-532.

37. Laatu S, Revonsuo A, Jaykka H, Portin R, Rinne JO: Visual object recognition in early Alzheimer's disease: deficits in semantic processing. Acta Neurol Scand 2003, 108:82-89.

Publish with Bio Med Central and every scientist can read your work free of charge

"BioMed Central will be the most significant development for disseminating the results of biomedical research in our lifetime. "

Sir Paul Nurse, Cancer Research UK

Your research papers will be:

- available free of charge to the entire biomedical community

- peer reviewed and published immediately upon acceptance

- cited in PubMed and archived on PubMed Central

- yours - you keep the copyright

Submit your manuscript here:

http://www.biomedcentral.com/info/publishing_adv.asp
BioMedcentral 